\title{
Detection of Circulating Tumor DNA in Human Blood via DNA-Mediated Surface-Enhanced Raman Spectroscopy of Single-Walled Carbon Nanotubes
}

Qifeng Zhou, Jing Zheng*, Zhihe Qing, Mengjie Zheng, Jinfeng Yang, Sheng Yang, Le Ying, Ronghua Yang*

Rolling circle amplification assay for KRAS G12DM detection ${ }^{1}$. Coupling the amplification primers to the surface of streptavidin-coated silica microbeads (SiMBs, $5 \mu \mathrm{m}$, purchased from Ocean Nanotech and dispersed at $0.1 \mathrm{mg} / \mathrm{mL}$ in $20 \mathrm{mM}$ PBS, $\mathrm{pH}$ 7.4). The oligonucleotide target in interest was hybridized to the padlock probe in $40 \mu \mathrm{L}$ of ligation buffer (30 mM Tris-HCl, $\left.\mathrm{pH} 7.8,4 \mathrm{mM} \mathrm{MgCl}_{2}, 0.1 \mathrm{MKCl}, 0.1 \mathrm{mM} \mathrm{NAD}^{+}\right)$during a 60 min incubation at $45^{\circ} \mathrm{C}$. Then, 3.6 U of T4 DNA ligase, $1 \mu \mathrm{L}$ of $2 \%$ BSA, $0.1 \mathrm{mg} / \mathrm{mL}$ SiMBs were added to the mixture. After another incubation at $37^{\circ} \mathrm{C}$ for $60 \mathrm{~min}$, the SiMBs were washed once using $200 \mu \mathrm{L}$ of solution of $50 \mathrm{mM}$ Tris- $\mathrm{HCl}, 50 \mathrm{mM} \mathrm{KCl}$, and 10 $\mathrm{mM} \mathrm{MgCl}$. Polymerization was carried out at $37{ }^{\circ} \mathrm{C}$ for $30 \mathrm{~min}$ in $40 \mu \mathrm{L}$ reaction buffer ( $40 \mathrm{mM}$ Tris- $\mathrm{HCl}, \mathrm{pH} 7.5,50$ $\mathrm{mM} \mathrm{KCl}, 10 \mathrm{mM} \mathrm{MgCl} 2,5 \mathrm{mM}\left(\mathrm{NH}_{4}\right)_{2} \mathrm{SO}_{4}, 4 \mathrm{mM}$ DTT) with $1 \mathrm{U} / \mu \mathrm{L}$ Taq polymerase and $625 \mu \mathrm{M}$ dNTPs. The SiMBs were washed again with $10 \mathrm{mM}$ phosphate buffer (pH7.4), and 10000 $\times \operatorname{Sybr~Gold~}^{\circledR}($ excitation $495 \mathrm{~nm}$, emission $540 \mathrm{~nm}$ ) was added to the mixture and wash again. Finally, the beads were resuspended in $500 \mu \mathrm{L}$ of PBS and analyzed on PTI QM4 Fluorescence System (Photo Technology International, Birmingham, NJ).

Table S1. Oligonucleotides Used in This Work*

\begin{tabular}{|c|c|}
\hline Entry & Sequences(5'-3') \\
\hline $\mathrm{T} 1$ & TAC GCC ATC AGC TCC \\
\hline $\mathrm{T} 2$ & TAC GCC ACC AGC TCC \\
\hline $\mathrm{CP} 1$ & TCTTTC GGAGCTGA $\mathrm{R}$ TGCGTA GAAAGA \\
\hline $\mathrm{CP} 2$ & TCTTTCT GGAGCTGA ${ }_{R}$ TGGCGTA AGAAAGA \\
\hline $\mathrm{CP} 3$ & TCTTTCTT GGAGCTGA ${ }_{R}$ TGGCGTA AAGAAAGA \\
\hline $\mathrm{CP} 4$ & TCTTTCTTT GGAGCTGA ${ }_{R}$ TGGCGTA AAAGAAAGA \\
\hline T3(c. $1624 \mathrm{G}>\mathrm{A})$ & AGTGATTTTAGAGAGAG \\
\hline PIK3CA E542KN & AGTGATTTCAGA GAGAG \\
\hline CP5 & TCTTTC CTCTCTCTAR AAATCACT GAAAGA \\
\hline CP6 & TCTTTCT CTCTCTCTA $_{R}$ AAATCACT AGAAAGA \\
\hline CP7 & TCTTTCTT СТСТСТСТА \\
\hline CP8 & TCTTTCTTT СТСТСТСТӒ \\
\hline A 20 & AAAAAAAAAAAAAAAAAAAA \\
\hline $\mathrm{T} 20$ & TTTTTTTTTTTTTTTTTTTT \\
\hline $\mathrm{C} 20$ & СССССССССССССССССССС \\
\hline $\mathrm{G} 20$ & GGGGGGGGGGGGGGGGGGGG \\
\hline $\mathrm{R} 20$ & ATCGATCGATCGATCGATCG \\
\hline T-rich ssDNA & HS-TTTTTTCTTTCTTTTTTTTTTTT \\
\hline KRAS G12DM for RCA & ACTCTTGCCTACGCCATCAGCTCC AAC TAC CAC AAG TTT \\
\hline Padlock probe & $\begin{array}{l}\text { phosphate-TGGCGTAGGCAAGATAGAATGAAGATAGCGCATCGTAGGACTTATTTCGT- } \\
\text { AGGACTTAGGGTAGTTGGAGCTGA }\end{array}$ \\
\hline primer & biotin-AAAAAAAAAAAAAAAATGCGCTATCTTCA \\
\hline
\end{tabular}


Table S2. The comparison results for KRASG12DM attained from RCA and our SERS assay

\begin{tabular}{|c|c|c|c|c|c|}
\hline & $\begin{array}{l}\text { Spiking } \\
\text { conc(nM) }\end{array}$ & $\begin{array}{l}\text { SERS } \\
\text { detected } \\
\text { conc }\end{array}$ & $\begin{array}{l}\text { Recovery } \\
(\%)\end{array}$ & $\begin{array}{c}\text { RCA } \\
\text { detected } \\
\text { conc(nM) }\end{array}$ & $\begin{array}{c}\text { Recovery } \\
(\%)\end{array}$ \\
\hline \multirow{2}{*}{$\begin{array}{l}\text { Buffer } \\
\text { solution }\end{array}$} & 0.050 & $\begin{array}{c}0.051 \pm 0.001 \\
\mathrm{nM}\end{array}$ & 102 & ND & ND \\
\hline & 1.0 & $\begin{array}{c}0.94 \pm 0.02 \\
\mathrm{nM}\end{array}$ & 94 & $0.96 \pm 0.01$ & 96 \\
\hline \multirow{2}{*}{$\begin{array}{l}\text { Patient } \\
\text { plasma }\end{array}$} & 0 & $\begin{array}{c}0.018 \pm 0.001 \\
\mathrm{pM}\end{array}$ & - & ND & ND \\
\hline & 1.0 & $\begin{array}{c}0.98 \pm 0.02 \\
\mathrm{nM}\end{array}$ & 98 & $0.97 \pm 0.01$ & 97 \\
\hline
\end{tabular}

*ND, cannot be detected

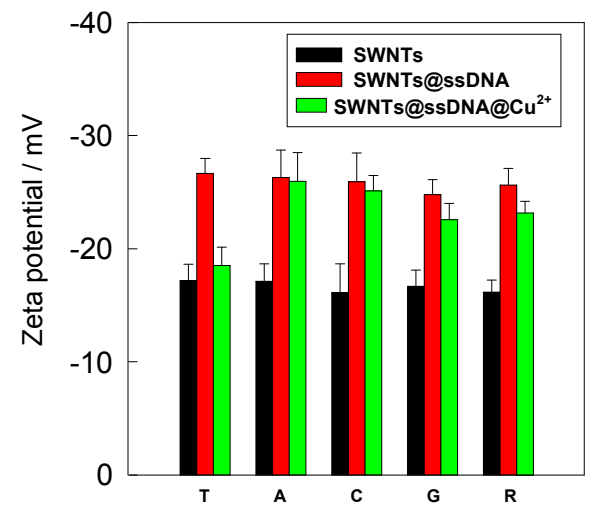

Figure S1. Zeta-potentials of SWNTs, T20, A20, C20, G20 and R20@SWNTs, and T20, A20, C20, G20 and R20-mediated SWNT@CuNPs. 


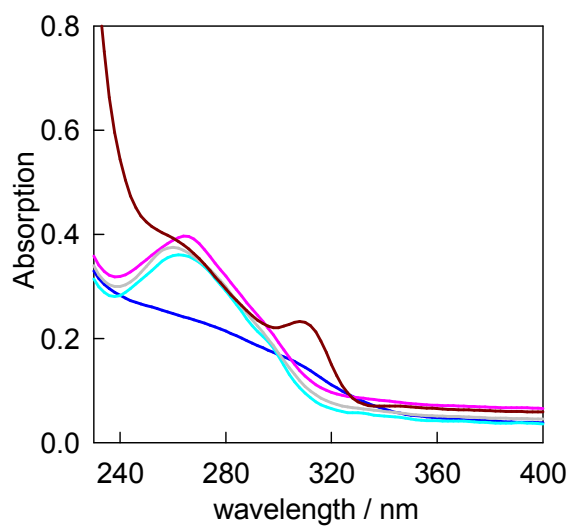

Figure S2. (A) Representative absorption spectra of bare SWNTs (blue), A20(gray), T20(brown), C20(pink), and G20(cyan) -mediated SWNT@CuNPs.

(A)

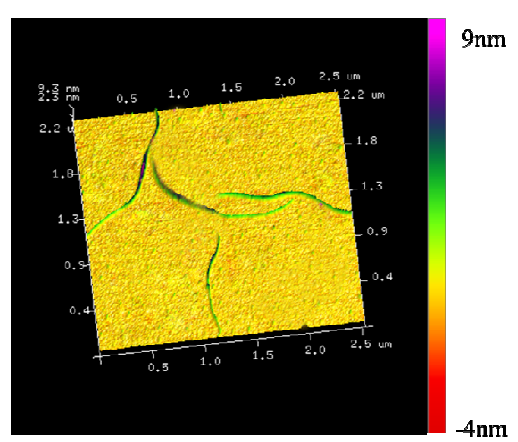

(B)
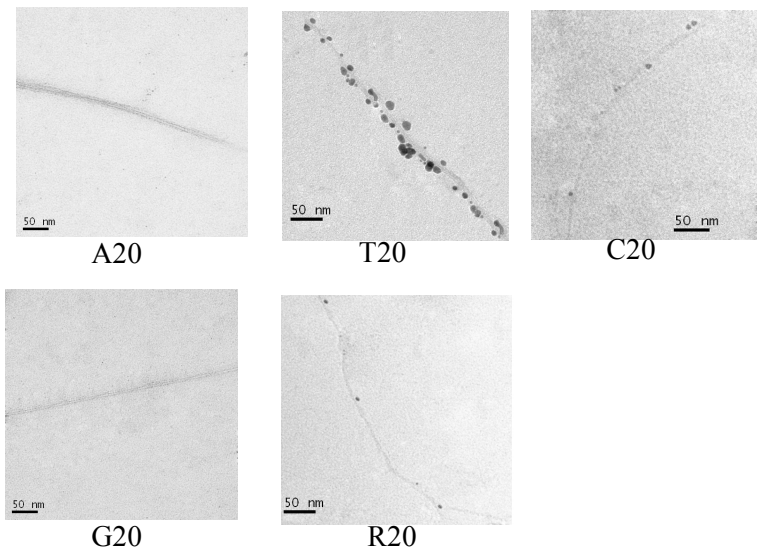

Figure S3. (A) Representative AFM image of the SWNT/T20 complex. (B) Representative TEM images of A20, T20, C20, G20 and R20-mediated SWNT@CuNPs. 


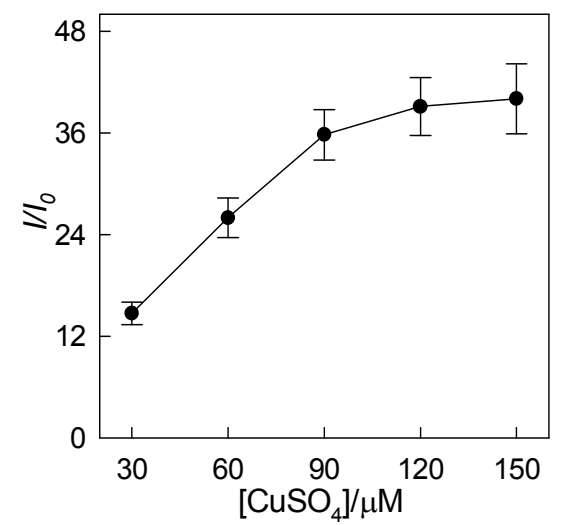

Figure S4. SERS intensity enhancements of the $1605 \mathrm{~cm}^{-1}$-band of SWNT@CuNPs in the absence $\left(I_{0}\right)$ and presence $(I)$ of T20. I/I , plotted against the concentration of $\mathrm{CuSO}_{4}$. All error bars were obtained through the detection of six parallel samples. $[\mathrm{T} 20]=100 \mathrm{nM},\left[\mathrm{Na}_{3} \mathrm{C}_{6} \mathrm{H}_{5} \mathrm{O}_{7}\right]=2 \mathrm{mM}$. The concentration of SWNT is excessive.

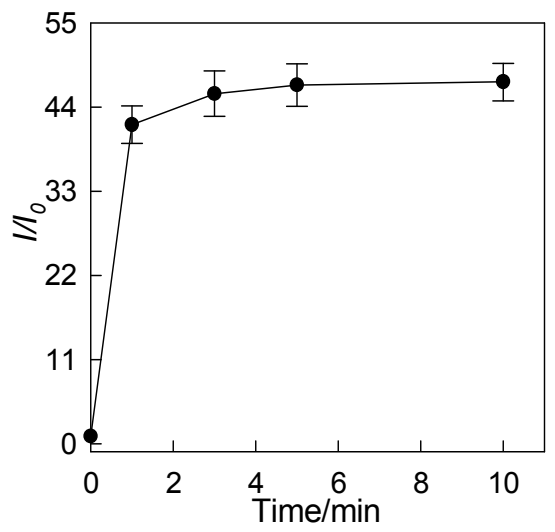

Figure S5. SERS intensity enhancements of the $1605 \mathrm{~cm}^{-1}$-band of SWNT@CuNPs in the absence $\left(I_{0}\right)$ and presence $(I)$ of T20. $I / I_{0}$, plotted against the CuNPs growth time. All error bars were obtained through six parallel samples. $[\mathrm{T} 20]=100 \mathrm{nM},\left[\mathrm{Na}_{3} \mathrm{C}_{6} \mathrm{H}_{5} \mathrm{O}_{7}\right]=2 \mathrm{mM}$. The concentration of SWNT is excessive. 


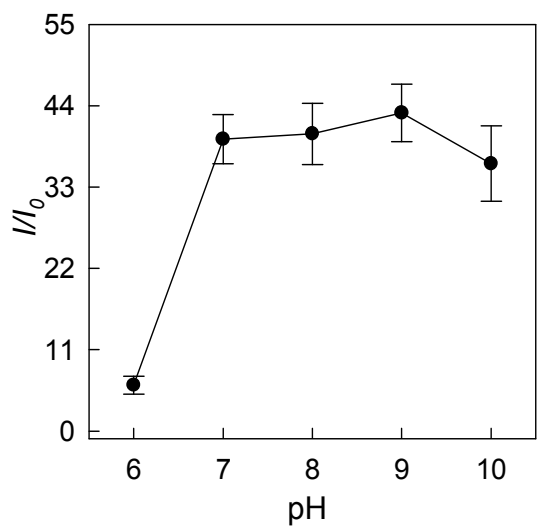

Figure S6. Effect of pH on the SERS intensity enhancements of the $1605 \mathrm{~cm}^{-1}$-band of SWNT@CuNPs in the absence $\left(I_{0}\right)$ and presence $(I)$ of T20. I/I $I_{0}$, plotted against $\mathrm{pH}$. [T20] $=100 \mathrm{nM},\left[\mathrm{Na}_{3} \mathrm{C}_{6} \mathrm{H}_{5} \mathrm{O}_{7}\right]=2 \mathrm{mM}$. The concentration of SWNT was excessive.
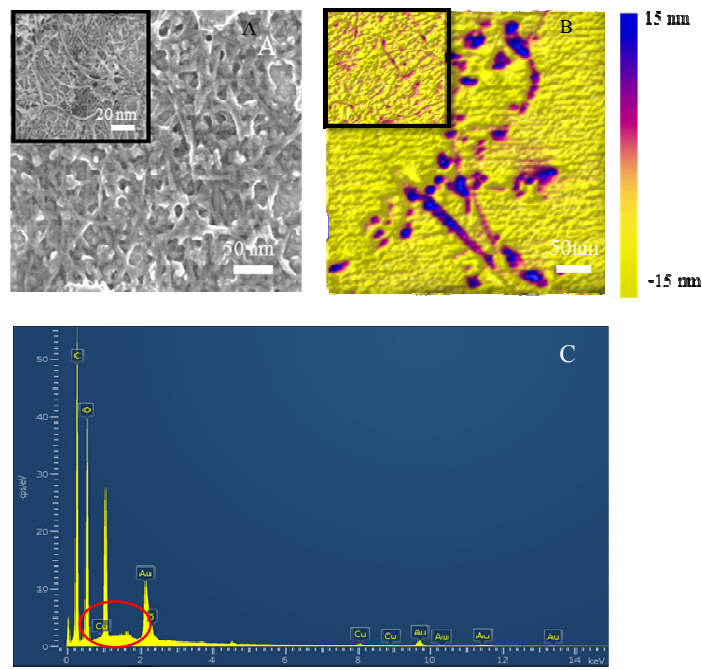

Figure S7. Characterization of T-rich ssDNA-mediated SWNT@CuNPs nanocomposites-based SERS substrate. (A) Representative SEM image of T-rich ssDNA-mediated SWNT@CuNPs on the surface of Au film. Inset: the T-rich ssDNA-mediated SWNT-functionalized Au film. (B) Representative AFM image of T-rich ssDNA-mediated SWNT@CuNPs on the surface of Au film. Inset: the T-rich ssDNA-mediated SWNT-functionalized Au film. (C) EDS of the T-rich ssDNA-mediated SWNT@CuNPs on the surface of Au film under the STEM pattern and red circle represents $\mathrm{Cu}$ element. 


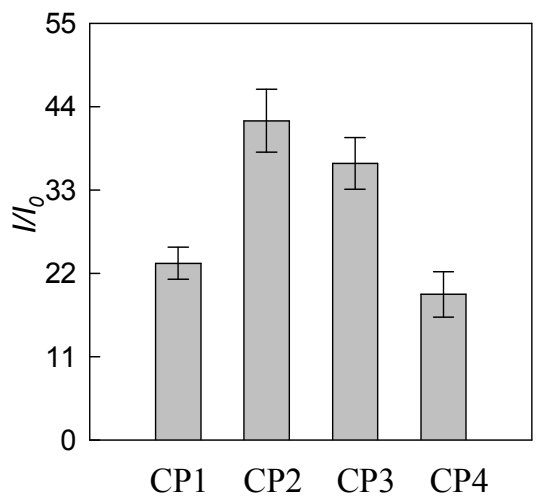

Figure S8. SERS signal enhancement of the $1605 \mathrm{~cm}^{-1}$-band of the SWNT@CuNPs nanocomposites with different capture probes (CP1-CP4) in the absence $\left(I_{0}\right)$ and presence $(I)$ of T1. $I / I_{0}$, plotted against CP1-4. The measuring conditions as shown in Figure 3A.

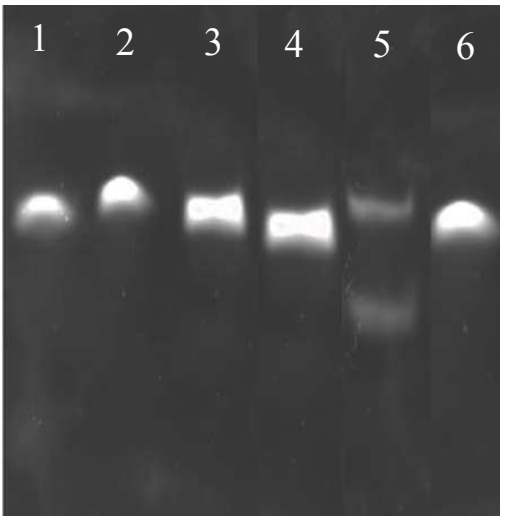

Figure S9. Agarose gel electrophoresis analysis of RNase HII-catalyzed cleavage mechanism. Lane 1: CP2; Lane 2: the CP2/T1 hybrid duplex; Lane 3: the CP2/T2 hybrid duplex; Lane 4: CP2 separately incubated with RNase HII; Lane 5: the CP2/T1 hybrid duplex after incubated with RNase HII; Lane 6: CP2/T2 hybrid duplex after incubated with RNase HII. All CP2 used in this electrophoresis are fluorescein-labeled. 


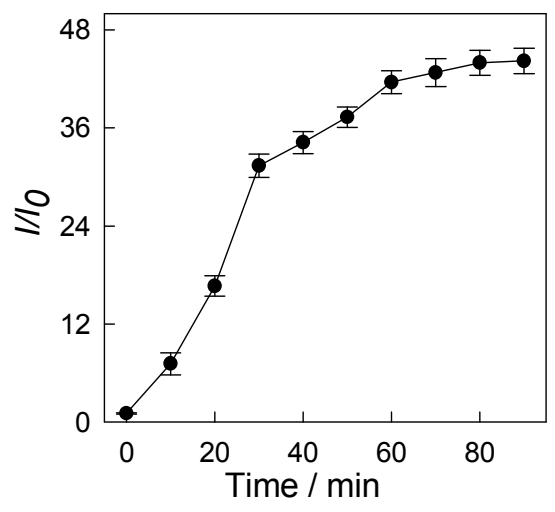

Figure S10. Effect of reaction time of RNase HII on the SERS intensity enhancements of the $1605 \mathrm{~cm}^{-1}$-band of the SWNT@CuNPs in the absence $\left(I_{0}\right)$ and presence $(I)$ of T1. $I / I_{0}$, plotted against the reaction time of RNase HII (from 0 to $90 \mathrm{~min})$. The measuring conditions as shown in Figure 3A.

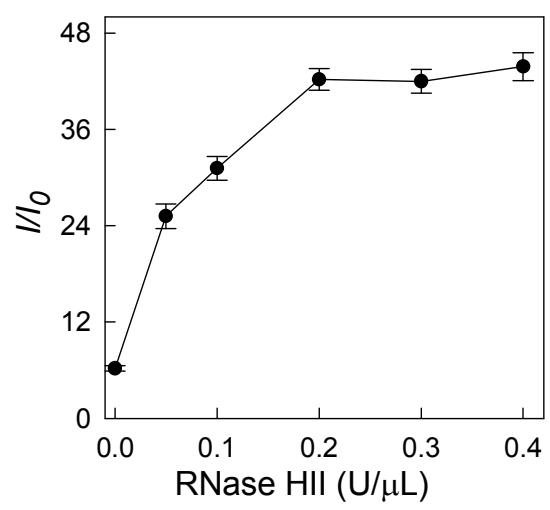

Figure S11. Effect of concentration of RNase HII on the SERS intensity enhancements of the $1605 \mathrm{~cm}^{-1}$-band of SWNT@CuNPs in the absence $\left(I_{0}\right)$ and presence $(I)$ of T1. I/I $I_{0}$, plotted against the concentration of RNase HII. The measuring conditions as shown in Figure 3A. 


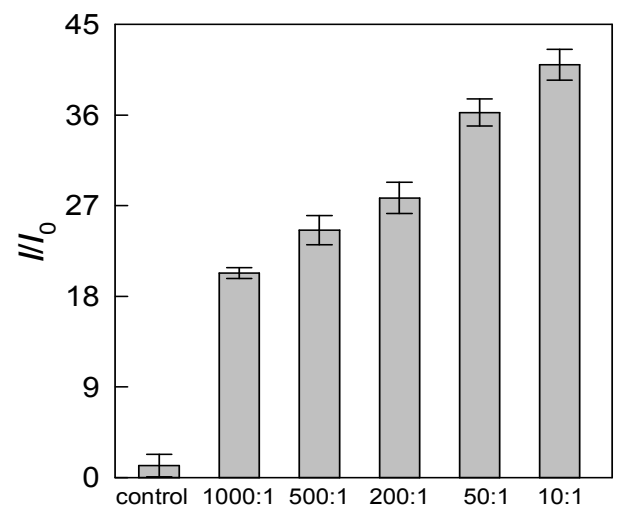

Figure S12. Selectivity of this SERS-based ctDNA sensing platform for KRAS. Histogram showing the capacity to measure the perfect-matched target in a mixture of T2 and T1. The mole ratios of T2 and T1 is 1000:0 (control), 1000:1, 500:1, 200:1, 50:1, 10:1 respectively with a total concentration of $10 \mathrm{nM}$. The standard deviations obtained by three repeated measurements are shown as the error bars. The measuring conditions as shown in Figure 3A.

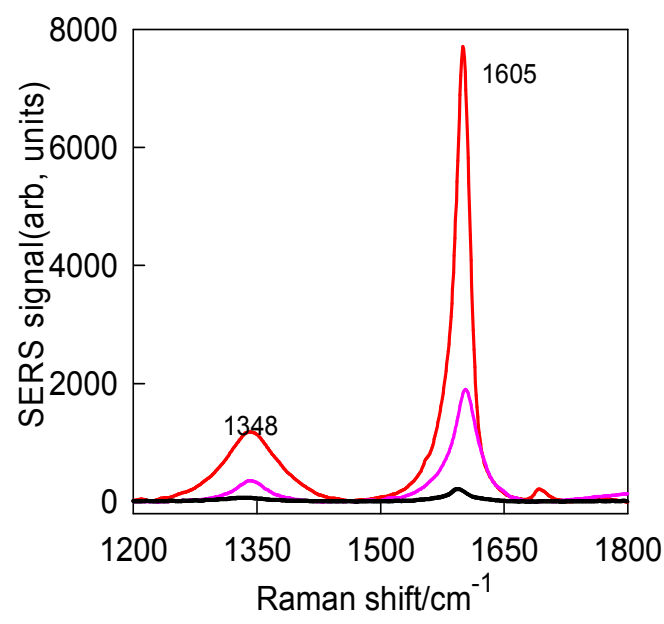

Figure S13. Representative SERS spectrum of the SWNT@CuNPs nanocomposites on the surface of Au film upon T1 extracted from cancer tissue (red curve) and para-carcinoma tissue (pink curve) addition. The spectrum of the SWNT@CuNPs nanocomposites without KRAS G12D addition is shown as black curve. The measuring conditions as shown in Figure 3A. 


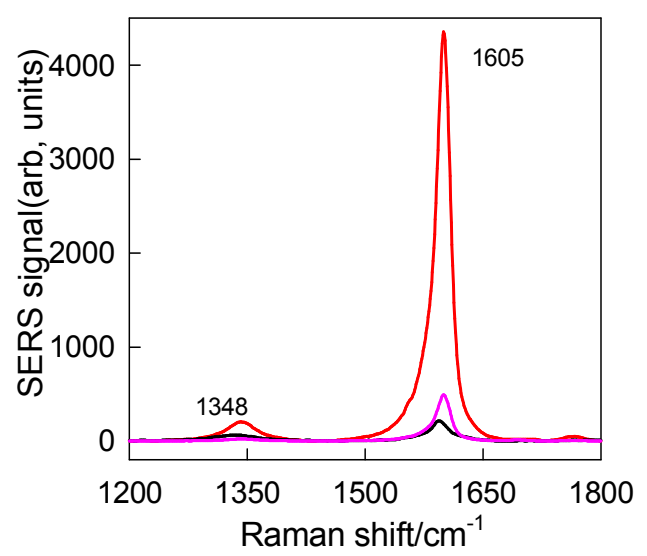

Figure S14. Representative SERS spectrum of the SWNT@CuNPs nanocomposites on the surface of Au film upon addition of patient (red curve) and healthy (pink curve) human serum. The spectrum of the SWNT@CuNPs nanocomposites without human serum addition is shown as black curve. The measuring conditions as shown in Figure $3 \mathrm{~A}$.

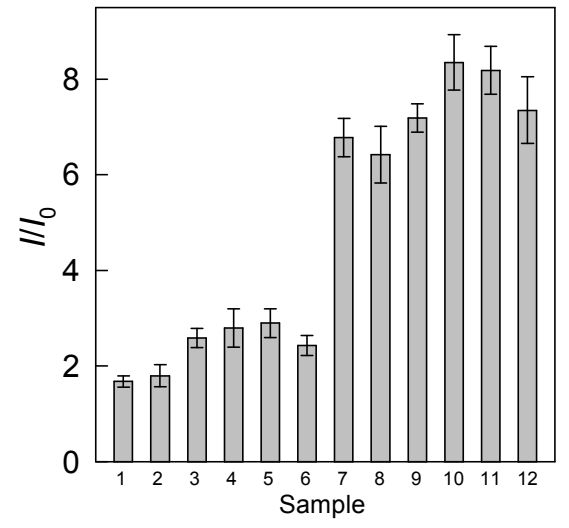

Figure S15. Histogram showing the results from six healthy (1-6) and six patients (7-12) with colon cancer. The measuring conditions as shown in Figure 3A. 


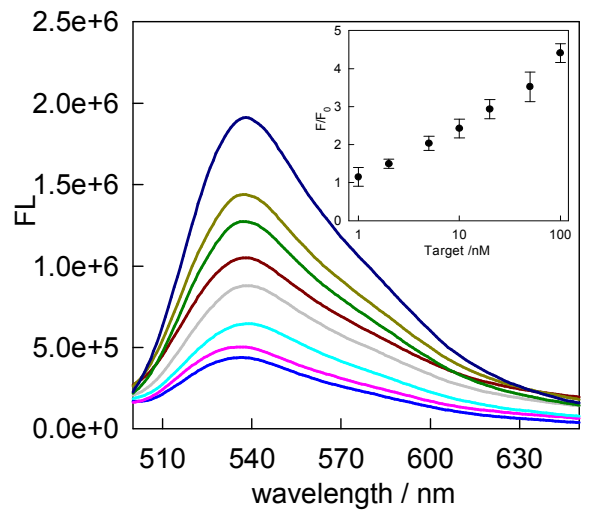

Figure S16. Fluorescence emission spectra of $10000 \times$ Sybr Gold ${ }^{\circledR}$ in PBS buffer solution (pH 7.4) upon addition of different concentrations of target $(0,1,2,5,10,20,50,100 \mathrm{nM})$. Inset: $\mathrm{F} / \mathrm{F}_{0}$, plotted against the concentration of target KRAS G12DM..

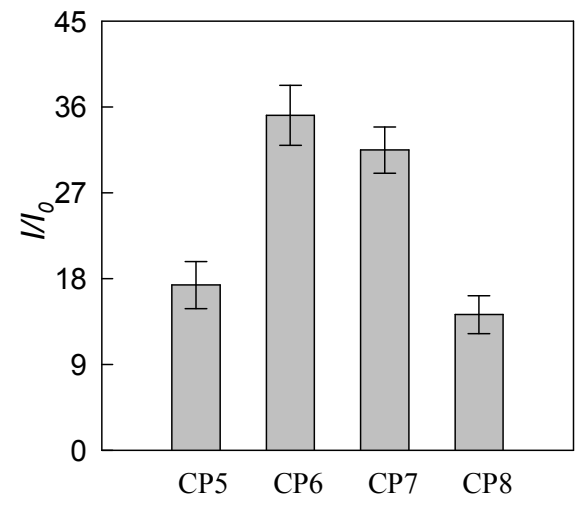

Figure S17. SERS signal enhancement of the $1605 \mathrm{~cm}^{-1}$-band of the SWNT@CuNPs nanocomposites with different capture probes (CP5-8) in the absence $\left(I_{0}\right)$ and presence $(I)$ of T3. The measuring conditions as shown in Figure 3A. $[\mathrm{T} 3]=10 \mathrm{nM}$. All error bars were obtained through the detection of six parallel samples. 


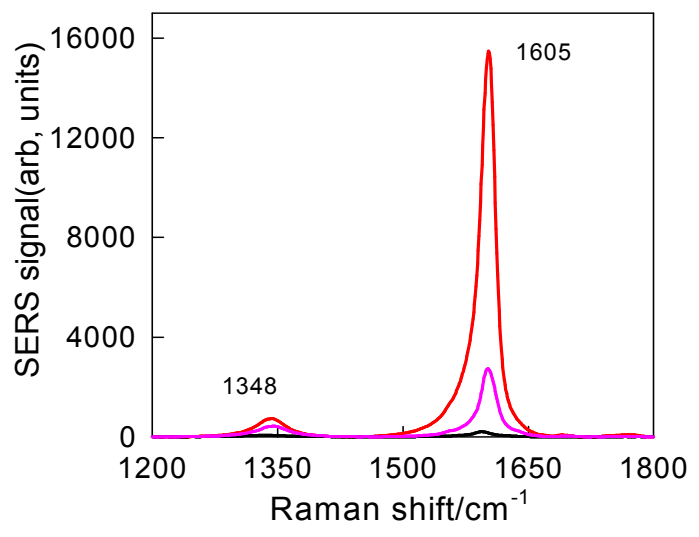

Figure S18. SERS spectra of SWNT@CuNPs before (black curve) and upon T3 addition without (pink curve) and with (red curve) RNase HII-aided amplification. The measuring conditions as shown in Figure 3A. [T3]=10nM.

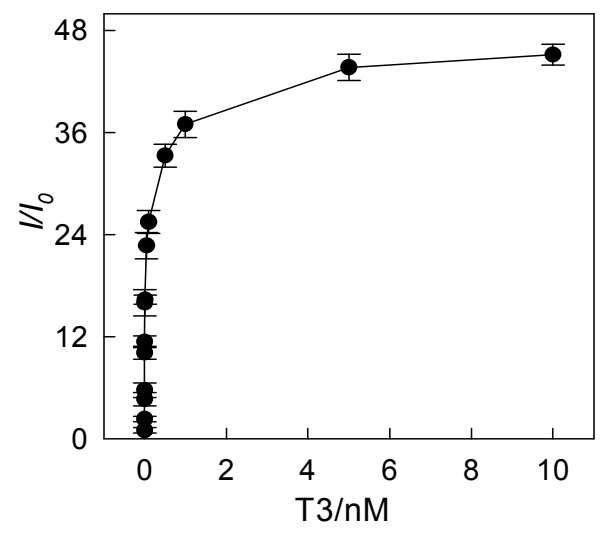

Figure S19. SERS intensity enhancements of the $1605 \mathrm{~cm}^{-1}$-band of SWNT@CuNPs nanocomposites in the absence $(I)$ and presence $\left(I_{0}\right)$ of T3, I/I 0 , plotted against the concentration of T3 with RNase HII-aided amplification. The measuring conditions as shown in Figure 3A. 


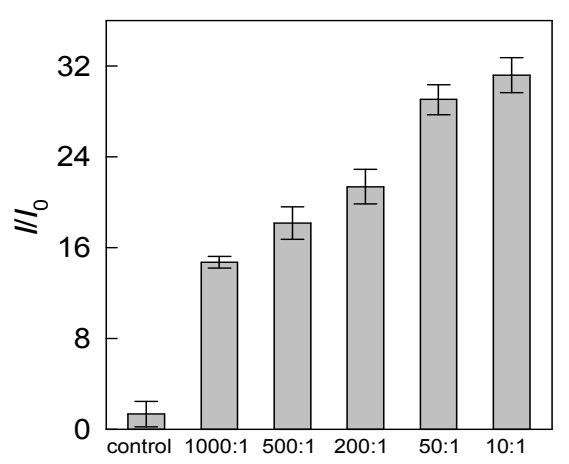

Figure S20. Selectivity of this SERS-based ctDNA sensing platform for PIK3CA E542KM detection. Histogram showing the capacity to measure the perfect-matched target in a mixture of T3 and T4. The mole ratios of T4 and T3 is 1000:0(control), 1000:1, 500:1, 200:1, 50:1, 10:1 respectively with a total concentration of $10 \mathrm{nM}$. The standard deviations obtained by three repeated measurements are shown as the error bars. The measuring conditions as shown in Figure 3A.

\section{REFERENCES}

[1] Li , J.; Zhong, W. Anal Chem. 2007, 79, 9030-9038. 